\title{
Pacjent jako obywatel. Autonomia pacjenta i obywatelskość na przykładzie Hiszpanii
}

\author{
Agata Strządała \\ https://orcid.org/0000-0002-3465-8025
}

Tekst dotyczy przemian pojmowania autonomii pacjenta w Hiszpanii, gdzie tradycyjnie $\mathrm{w}$ relacjach między lekarzem a pacjentem dominował paternalizm, a w sferze ideologicznej - nauczanie Kościoła katolickiego. Transformacja ustrojowa w kraju po upadku dyktatury Francisco Franco (1936-1975) doprowadziła do znaczących przeobrażeń również w kwestii bioetyki. Rosnące poczucie obywatelskości łączyło się tam ze wzrastaniem znaczenia autonomii pacjenta, co przejawia się na kilku poziomach: legislacyjnym (prawo o autonomii pacjenta), społecznym (organizacje pozarządowe aktywne w sferze opieki medycznej), świadomościowym (wzrost świadomości praw pacjenta, refleksyjne podejście do relacji z personelem medycznym), a także ideologicznym (krytyka paternalizmu, bioetyka obywatelska, krytyka komercjalizacji medycyny). Ponadto, o specyfice obecnej sytuacji w Hiszpanii decyduje przewartościowanie katolickiego dziedzictwa, odejście od nauczania Kościoła w obywatelskim modelu bioetyki, manifestujące się liberalizacją prawa aborcyjnego, prawa dotyczącego wspomaganej reprodukcji, preimplantacyjnej diagnostyki genetycznej i badań na embrionach.

Słowa kluczowe: autonomia pacjenta, paternalizm, społeczeństwo obywatelskie, Hiszpania

AGATA STRZĄDAŁA, doktor nauk humanistycznych, Zakład Humanistycznych Nauk Lekarskich, Wydział Lekarski, Uniwersytet Medyczny im. Piastów Śląskich we Wrocławiu; adres do korespondencji: Zakład Humanistycznych Nauk Lekarskich, Uniwersytet Medyczny, ul. J. Mikulicza-Radeckiego 7, 50-368 Wrocław; e-mail: agata.strzadala@umed.wroc.pl 
Współczesna Hiszpania przechodzi przez dynamiczne przemiany społeczno-kulturowe, wykształcenie się społeczeństwa obywatelskiego przyczyniło się tam między innymi do wzmocnienia niezależności i emancypacji pacjentów, a także do przemian pojmowania kwestii bioetycznych. Społeczeństwo obywatelskie opiera się na pojęciu obywatela, którego znamionuje polityczna wolność i podmiotowość. Obywatel nie jest jak dawniej poddanym, ale sam o sobie stanowi, aktywnie współuczestniczy w kształtowaniu rzeczywistości społeczno-politycznej. Zarówno obywatel, jak i autonomiczny pacjent mają prawo do informacji, świadomie je przetwarzają i na ich podstawie podejmują decyzje.

Paternalizm i autonomia pacjenta $\mathrm{w}$ literaturze przedmiotu są przeciwstawiane jako wykluczające się rodzaje relacji między lekarzem a pacjentem ${ }^{1}$. Paternalizm oznacza bowiem zdawanie się na autorytet personelu medycznego, który wspiera rodziny w podejmowaniu decyzji dotyczących leczenia i postępowania z chorymi. Osąd lekarza uznaje się za wiarygodny i rozstrzygający. Natomiast szacunek dla pacjenta opiera się na przekonaniu, że pacjent powinien być informowany o swoim stanie zdrowia, opcjach, kosztach i ryzykach postępowania medycznego, a także na tym, że to w jego gestii leży podjęcie ostatecznej zgody lub odmowy leczenia. Problematyka autonomii wiąże się z uznaniem względnej niezależności pacjenta wobec władzy lekarza, respektowaniem jego preferencji, poglądów czy stylu życia, co odzwierciedlać się może w realizowaniu np. wolności prokreacyjnej. Autonomia pacjenta stanowi więc jeden z przejawów obywatelskiej podmiotowości realizowanej w zakresie opieki medycznej. Paternalizmowi sprzyjają natomiast bardziej autorytarne formy władzy.

Celem artykuły jest wykazanie roli, jaką w przemianach postrzegania zagadnień bioetycznych odgrywa wzrastające poczucie obywatelskości Hiszpanów. Wzrost autonomii pacjentów i słabniecie paternalizmu zanotować możemy w Hiszpanii na kilku poziomach: legislacyjnym (wprowadzenie prawa, gdzie kategoria autonomii pacjenta odgrywa kluczową rolę, przemiany prawa reprodukcyjnego), świadomościowym (wzrastająca znajomość praw pacjentów), społecznym (rosnąca rola organizacji pozarządowych w świadczeniu i organizowaniu opieki zdrowotnej) oraz na poziomie ideologicznym, wyrażanym poprzez teorie

\footnotetext{
${ }^{1}$ Vikki A. Entwistle, Stacy M. Carter, Alan Cribb, Kirsten McCaffery, „Supporting patient autonomy: the importance of clinician-patient relationships", Journal of general internal medicine 25, nr 7 (2010): 741-745, DOI:10.1007/s11606-010-1292-2
} 
bioetyki obywatelskiej. Bioetyka obywatelska w Hiszpanii podnosi kwestię autonomii, ale nie identyfikuje jej z indywidualistycznie i liberalnie rozumianymi preferencjami pacjentów ${ }^{2}$, lecz z poczuciem obywatelskości, która uwzględnia odpowiedzialność społeczną, zarówno w indywidualnych decyzjach medycznych, jak i w kształtowaniu opieki medycznej w kraju.

\section{Organizacje obywatelskie a autonomia pacjenta}

Królestwo Hiszpanii, zarówno pod względem powierzchni, jak i liczby ludności, jest jednym z największych krajów Europy. Jego populacja, która wynosi obecnie prawie $47 \mathrm{mln}$. ludzi, wyróżnia się bardzo wysoką średnią oczekiwaną długością życia - przekraczającą 83 lata. Ogólnej, dobrej sytuacji zdrowotnej na Półwyspie Iberyjskim zaczyna zagrażać gwałtowne starzenie się społeczeństwa (wskaźnik urodzin na jedną kobietę w 2019 r. wynosił jedynie 1,4 dziecka). Napływ migrantów, którzy w ciągu ostatnich 10 latach nieco odmłodził hiszpańskie społeczeństwo, może nieznacznie spowalniać ten proces. Głównymi przyczynami śmierci w kraju są choroby sercowo-naczyniowe, nowotwory i choroby układu oddechowego. W społeczeństwie spada liczba palących, ale narasta problem otyłości jako choroby cywilizacyjnej ${ }^{3}$.

Hiszpania od 1978 r. jest monarchią parlamentarną z wyraźnym podziałem regionalnym, co odzwierciedla się w sposobie organizacji opieki medycznej, która jest zregionalizowana i zdecentralizowana. Przemiany demokratyczne w kraju, po upadku frankistowskiej dyktatury, mają swoje odbicie również w pluralizacji opieki medycznej, a także dyskursu bioetycznego, który wcześniej był zdominowany przez myśl katolicką i tradycyjny w krajach śródziemnomorskich paternalizm.

Podobnie jak inne wysoko rozwinięte gospodarczo społeczeństwa - Hiszpania, mimo zwiększającej się długości i jakości życia, opanowaniu wielu chorób zakaźnych i niskiej śmiertelności niemowląt - zmaga się z nowego typu wyzwaniami

\footnotetext{
${ }^{2}$ Por. Anne M. Stiggelbout, Bert Molewijk, Wilma Otten, Roxana Timmermans, „Ideals of patient autonomy in clinical decision making: a study on the development of a scale to assess patients' and physicians' views", Journal of medical ethics 30, nr 3 (2004): 268-274, DOI:10.1136/jme.2003.003095

${ }^{3}$ Sandra García-Armesto, María Begoña Abadía-Taira, Antonio Durán, Cristina Hernandez-Quevedo, „Spain: Health System Review 2010”, Health System in Transition 12, nr 4 (2010): XX-XXIII.
} 
w zakresie opieki zdrowotnej: przewagą chorób chronicznych i starzejącym się społeczeństwem, które są trudne do opanowania nie tylko z medycznego, ale i finansowego punktu widzenia. Jednocześnie opieka zdrowotna w tych państwach, jak stwierdza zgodnie wielu autorów, coraz bardziej podlega regulacjom wolnego rynku i neoliberalnej polityki finansowej ${ }^{4}$. Ponadto, wzrastający indywidualizm i komercjalizacja usług medycznych sprawiają, że relacje między pacjentami a dostarczycielami opieki zdrowotnej przekształcają się w układ klient - sprzedawca. Stwarza to zagrożenia społeczne, zdrowotne i ekonomiczne: wiele decyzji może być podyktowanych rachunkiem finansowym lub nierealistycznymi oczekiwaniami „klientów”, które rozmijać się mogą z dobrem samego chorego, a z drugiej strony - $z$ dobrem publicznym i bezpieczeństwem całego społeczeństwa. Pojawia się zatem pytanie o rolę państwa, czy powinna być ona zredukowana, czy wręcz przeciwnie - to zadaniem państwa jest stanie na straży interesu publicznego, balansowanie interesów jednostek, aby na przykład zapewnić długofalowe rozwiązania w przypadku chorób degeneracyjnych, procedury w wypadku groźnych epidemii, czyli kwestii nieuwzględnianych przy jednostkowych transakcjach medyczno-konsumerystycznych.

Przykładem komercjalizacji rynku usług medycznych jest Wielka Brytania, gdzie dostarczycielami opieki medycznej mogą być instytucje państwowe, pozarządowe organizacje for-profit, a także non-profit ${ }^{5}$. Państwo w większym stopniu jest tu koordynatorem między poszczególnymi dostarczycielami usług a pacjentami, kontraktując określony zakres usług medycznych z różnymi typami organizacji. Prywatna opieka medyczna, płatna $z$ dodatkowych ubezpieczeń lub opłat ponoszonych przez samych pacjentów, istnieje, ale odgrywa rolę marginalną. W Niemczech natomiast państwo jest głównym dostarczycielem opieki zdrowotnej, pacjent może jednak wybierać między państwową a prywatną służbą zdrowia (płatną z dodatkowego prywatnego ubezpieczenia), działając w swoim najlepszym interesie, nie tylko zdrowotnym, ale i finansowym. Istotną cechą krajów gospodarczo i obywatelsko rozwiniętych jest też spory udział organizacji pozarządowych w zapewnieniu opieki zdrowotnej, choćby w wybranych sektorach społecznych. W krajach rozwijających się natomiast w sytuacji słabości państwa (jeśli idzie o finanse, możliwości organizacyjne i infrastrukturalne) dominuje sektor

\footnotetext{
${ }^{4}$ Zob. Guido Giarelli, Ellen Annandale, „Introduction: the role of civil society in healthcare system reforms", Social Science and Medicine 2014, nr 123: 160-167.

${ }^{5}$ Tamże, 160.
} 
prywatny oraz rozmaici nieformalni dostarczyciele opieki zdrowotnej (medycyna tradycyjna) $)^{6}$, brakuje natomiast rozwiniętego wachlarza organizacji pozarządowych, zdolnych wypełnić luki w państwowym i prywatnym systemie opieki zdrowotnej.

Jak proponują Guido Giarelli i Ellen Annandale sposobem wyjścia Hiszpanii z patowej sytuacji - z jednej strony presji komercyjnego sektora prywatnego, $\mathrm{z}$ drugiej ryzyka popadnięcia w centralnie sterowany system państwowej opieki zdrowotnej, który w dzisiejszym kontekście jest nieefektywny i nierentowny - mogą być organizacje pozarządowe. Badacze Ci odwołują się przy tym do etosu społeczeństwa obywatelskiego, sięgającego korzeniami oświecenia oraz idei opisanych przez Alexisa de Tocqueville, który w zrzeszeniach obywatelskich upatrywał siłę i istotę demokracji ${ }^{7}$. Idea suwerenności narodu, czyli samostanowienia dzięki obieralnym przedstawicielom, jest tylko jednym z elementów prawdziwej demokracji, jej siła drzemie w samorządzie, oddolnych inicjatywach dobrowolnych ludzkich wspólnot, spontanicznych stowarzyszeniach politycznych, spółkach gospodarczych:

A przecież właśnie $\mathrm{w}$ gminie tkwi siła wolnych społeczeństw. Instytucje gminne są dla wolności tym, czym dla nauki są szkoły podstawowe: sprawiają, że wolność staje się dostępna dla ludu, pozwalają mu zasmakować w swobodnym jej praktykowaniu i przyzwyczajają go do posługiwania się nią. Bez pomocy instytucji gminnych naród może stworzyć sobie wolny rząd, lecz nie będzie w nim ducha wolności. Przelotne namiętności, chwilowe potrzeby czy przypadkowe okoliczności mogą mu dać zewnętrzne formy niezależności, lecz despotyzm ukryty we wnętrzu organizmu społecznego wcześniej czy później wyjdzie na jaw.

Duch obywatelskości, jak przekonywał de Tocqueville, bierze się z powszechnych praw politycznych obywateli, które są egzekwowane i szanowane przez władze państwowe. Koncepcja społeczeństwa obywatelskiego została dużo później użyta do opisu transformacji państw bloku wschodniego, kiedy ludzie zaczęli się

${ }^{6}$ Tamże, 161.

${ }^{7}$ Alexis de Tocqueville, O demokracji w Ameryce, tłum. Marcin Król (Warszawa: Państwowy Instytut Wydawniczy, 1976).

${ }^{8}$ Tamże, 66. 
samodzielnie organizować w opozycji do zdyskredytowanej władzy komunistycznej'.

Obywatelska aktywność przejawia się w różnych formach organizacji społecznej, mogą to być instytucje o sformalizowanym charakterze, jak zarejestrowane organizacje pozarządowe, określane mianem trzeciego sektora, posiadające swoją wewnętrzną strukturę, statut, sprecyzowane długofalowe cele, dysponujące własnym budżetem, działające $\mathrm{w}$ interesie publicznym. Może jednak przybierać formy mniej ustrukturyzowane, jak bardziej spontaniczne ruchy obywatelskie, mające raczej interwencjonistyczny charakter, formujące się tymczasowo w odpowiedzi na określoną sytuację kryzysową. Zdarza się, że z ruchów obywatelskich wyłaniają się właśnie późniejsze organizacje pozarządowe, związki zawodowe, partie polityczne etc. Oprócz tego, występuje cały wachlarz organizacji obywatelskich, zrzeszeń o różnym stopniu zorganizowania, łączących ludzi ze względu na ich zainteresowania, przynależność do tej samej grupy społecznej lub zawodowej czy wspólne cele.

Organizacje pozarządowe często określa się za Jürgenem Habermasem jako „ani państwo, ani rynek, ani rodzina”"10, wskazując na ich miejsce pośrednie między więzami osobistymi a bezosobowymi instytucjami publicznymi, łączącymi się z odgórną władzą. Stowarzyszenia, ruchy miejskie, kościoły, organizacje działające w sferze publicznej dla wspólnotowych interesów, ale niezależne wobec państwa, samorządne, dobrowolne i spontaniczne, opierające się na wolontariacie, tworzą tkankę społeczeństwa obywatelskiego. Zapewniają egalitarne i solidarnościowe funkcjonowanie państwa, dbając o realizowanie demokracji na najniższych stopniach politycznej i administracyjnej organizacji. Działają blisko zwykłych ludzi, dzięki czemu demokracja nie ogranicza się jedynie do udziału w wyborach do centralistycznych struktur władzy państwowej.

Organizacje obywatelskie zapobiegają anomii i alienacji we współczesnych społeczeństwach zachodnich, gdzie tradycyjne więzi wspólnotowe niejednokrotnie uległy zanikowi, lub straciły na znaczeniu. Służą też emancypacji marginalizowanych grup społecznych, zapewniają na przykład opiekę medyczną w tych sektorach czy obszarach, które nie są pokryte siecią państwowych lub prywatnych

\footnotetext{
${ }^{9}$ Jean L. Cohen, Andrew Arato, Civil Society and Political Theory (Cambridge MA: MIT Press, 1992).

${ }^{10}$ Jürgen Habermas, Legitimation Crisis, tłum. Thomas McCarty (Boston MA: Beacon Press, 1975).
} 
organizacji ${ }^{11}$. Np. stowarzyszenia zapewniające anonimowe i bezpłatne badania na nosicielstwo wirusa HIV $^{12}$ (państwowe badania nie są anonimowe, albo nie są bezpłatne), fundacje pomagające ludziom $z$ konkretnymi schorzeniami na przykład - bardzo rzadkimi, niebudzącymi zainteresowania sektora prywatnego ze względu na wysokie nakłady finansowe a niskie potencjalne zyski; grupy wsparcia dla chorych i ich rodzin etc. Wolontariusze pracują wśród grup najbiedniejszych i marginalizowanych, bezdomnych, narkomanów, prostytutek, migrantów, a także mniejszości etnicznych. Działają na rzecz podniesienia jakości i dostępności usług medycznych ${ }^{13}$. W Boliwii na przykład organizacje pozarządowe wraz z ruchami indiańskimi przyczyniły się do uznania przez państwo medycyny ludowej, a za tym przykładem poszło wiele innych krajów Ameryki Łacińskiej ${ }^{14}$. Dzięki ich działaniom wypełniły się luki w systemie opieki zdrowotnej, który nie obejmował małych, odizolowanych społeczności tradycyjnych, zdanych często na siebie.

Organizacje pozarządowe w opiece medycznej służą jako dostarczyciel usług medycznych (z środków własnych, darowizn lub państwowych subsydiów), reprezentują pacjentów w relacji z państwem lub sektorem prywatnym, dają głos grupom marginalizowanym, lub też dostarczają kapitału społecznego wy-alienowanym jednostkom (np. grupy wsparcia) ${ }^{15}$. Przemiany demokratyczne sprzyjają wzmacnianiu się autonomii pacjentów, dając im alternatywne roz-wiązania, opiekę nawet, gdy państwo lub sektor prywatny zawodzą.

Również w Hiszpanii ruchy obywatelskie coraz mocniej angażują się w kwestie opieki zdrowotnej. Organizacja Affinity Group of National Associations ${ }^{16}$ (ANGA), zrzeszająca ruchy obywatelskie na świecie, uznała, że największym ich osiągnięciem w Hiszpanii w latach 2014-2015 było powstrzymanie prywatyzacji

${ }^{11}$ Giarelli, Annandale, „Introduction”, 162.

${ }^{12} \mathrm{Na}$ przykład: „Statut Podwale 7”, http://podwale-siedem.pl/stowarzyszenie-statut/ (dostęp 24.09.2019).

${ }^{13}$ Civil Society and Health. Contribution and Potential, red. Scott L. Green, Matthias Wismar, Gabriel Pastorin, Monika Kosińska (UK: WHO, 2017).

${ }^{14}$ Deby Babis, „The role of civil society organizations in the institutionalization of indigenous medicine in Bolivia", Social Sciences in Medicine 2014, nr 123: 287-294.

${ }^{15}$ Giarelli, Annandale, „Introduction”, 166.

${ }^{16}$ „Affinity Group of National Associations AGNA”, https://www.civicus.org/index.php/whatwe-do/strengthen/agna (dostęp: 24.09.2019). 
systemu opieki zdrowotnej w Madrycie ${ }^{17}$. Hiszpańskie organizacje non-profit, obok publicznej i prywatnej służby zdrowia, dostarczają bezpośrednio usług medycznych (kontraktowane są na poziomie $15-20 \%$ przez państwo). Poza tym, są szczególnie aktywne i skuteczne w pomocy medycznej i prawnej ofiarom wypadków w miejscu pracy oraz w przypadku chorób zawodowych ${ }^{18}$.

Kwestie zdrowotne są jednymi $z$ istotnych tematów podejmowanych przez zrzeszenia obywatelskie w Hiszpanii, państwo nie jest jedynym źródłem opieki zdrowotnej, ponadto pojawiły się organizacje broniące praw i dobiegające roszczeń pacjentów wobec państwa czy prywatnych pracodawców.

\section{Prawo gwarantujące szacunek dla autonomii pacjenta oraz jego świadomość wśród obywateli}

Paternalizm, który w przeszłości dominował w krajach śródziemno-morskich, w ostatnich dekadach zaczął się kruszyć. Przede wszystkim autonomia pacjenta została uznana na poziomie legislacyjnym, w 2002 r. wprowadzono w Hiszpanii nową ustawę, oficjalnie proklamującą ideę szacunku dla autonomii pacjenta. Artykuł 2 mówi o świadomej zgodzie, która powinna poprzedzać wszelkie działania medyczne. Pacjent - zgodnie z nim - posiada prawo do informacji o stanie swojego zdrowia, alternatywnych opcjach leczenia, decydowania o sobie, a także - prawo do odmowy leczenia (za wyjątkiem poważnego zagrożenia dla zdrowia i życia innych np. w przypadku groźnej epidemii) ${ }^{19}$. Informacje o diagnozie, skutkach ubocznych, ewentualnym ryzyku leczenia należy zasadniczo udzielać ustnie. W przypadku operacji i poważnych interwencji medycznych oraz terapii niosących znaczne ryzyko, decyzja winna być sporządzona pisemnie. Podobnie świadoma zgoda zasadniczo może przybrać formę ustną, a jedynie bardziej inwazyjne procedury należy potwierdzać pisemnie. Kiedy pacjent ze względu na stan me-

${ }^{17}$ Ellena G. Sevillano, „Sanidad Reunicia Definitivamente a la Privatización Hospitalaria”, El Pais, 11.04.2014, https://elpais.com/ccaa/2014/04/11/madrid/1397239898_967369.html (dostęp 24.09.2019).

${ }^{18}$ Tamże.

${ }^{19}$ „Ley 41/2002, de 14 de noviembre, básica reguladora de la autonomía del paciente y de derechos y obligaciones en materia de información y documentación clínica", https://www.boe.es/buscar /doc.php?id=BOE-A-2002-22188 (dostęp: 24.09.2019). 
dyczny, wiek, swoje możliwości intelektualne i emocjonalne albo brak przytomności, nie jest zdolny, aby zrozumieć kierowane do niego informacje, ani podejmować decyzje, robi to za niego przedstawiciel prawny lub pełnomocnik. Jeśli nie został on wyznaczony, to decyzje podejmują osoby spokrewnione z pacjentem lub faktycznie będące z nim w związku (np. partnerskim). W przypadku osób niepełnoletnich, 16-latkowie są uznawani za w pełni kompetentnych, natomiast osoby od 12 do 16 roku życia mogą wyrażać swoje opinie i powinny być one brane pod uwagę. Zmiana prawa jest wyrazem głębszych przemian społecznych w Hiszpanii, postępującej demokratyzacji i wzrastającej autonomii pacjentów.

Nieznajomość praw pacjenta sprzyja utrzymywaniu się postaw pater-nalistycznych. Fakt, czy przestrzegają ich lekarze, też jest oczywiście niezwykle istotny, ale w kontekście społeczeństwa obywatelskiego, gdzie ludzie mogą zrzeszać w celu obrony wspólnych interesów, czasami wbrew władzy politycznej czy wpływowi korporacji biznesowych albo zawodowych, to samoświadomość pacjenta jest kluczem do pełnej autonomii. Państwo powinno stać na straży egzekucji praw, ale bez aktywnej roli jednostek w życiu publicznym, zarówno społeczeństwo obywatelskie, jak i autonomia pacjenta, są fikcją.

W krajach o wysokim paternalizmie, a jednocześnie dalekich od ideałów społeczeństwa obywatelskiego, często decydującą rolę ma postawa samych lekarzy. Przykładem może być sytuacja opisana przez Farhat Moazam w słynnym studium etnograficznym Bioethics and Organ Transplantation in a Muslim Society. A Study in Culture, Ethnography, and Religion (2006) ${ }^{20}$. W Pakistanie, gdzie nie ma programu pobierania organów od zmarłych, przeszczepy pobiera się wyłącznie od żywych dawców, a ponieważ ze względów ekonomicznych istnieje duże ryzyko handlu organami - nerki przeszczepia się tylko między członkami rodziny. Jednak o tym, kto powinien zostać dawcą, decydują czasem nie tyle kryteria czysto medyczne czy dobra wola potencjalnego dawcy, ale raczej powiązania i interesy klanowe. Unika się mianowicie pobierania nerek od młodych, nieżonatych mężczyzn (uważa się, że brak jednej nerki obniżyć może potencję i możliwości prokreacyjne dawcy). Preferuje się natomiast kobiety jako dawców, mimo że drastycznie obniża to możliwość ich zamążpójścia, a zatem w kontekście kultury, w której przeznaczeniem człowieka jest małżeństwo, skazuje się je na społeczną

\footnotetext{
${ }^{20}$ Farhat Moazam, Bioethics and Organ Transplantation in a Muslim Society. A Study in Culture, Ethnography, and Religion (Indianapolis: Indiana University Press, 2006).
} 
marginalizację, a nawet wykluczenie. Takim praktykom przeciwstawiają się lekarze, odmawiając operacji, która byłaby szkodliwa medycznie lub społecznie dla dawczyni. Społeczność z okolic Karachi, gdzie prowadzono badania, nie jest społeczeństwem obywatelskim, posiada wyraźną strukturę klanową. Obywatele choćby w idei powinni być równi, natomiast w klanie istnieje wyraźna hierarchia wewnętrzna, a ludzie postrzegani są nie tyle jako niezależne jednostki, ale jako członkowie grupy rodowej, ich zachowanie i wybory życiowe podyktowane są dobrem klanu.

W Hiszpanii paternalizm łagodnieje za sprawą wzrastającej obywatelskości mieszkańców Półwyspu Iberyjskiego. Jak pisze José Joaquín Mira, współautor badań nad świadomością społeczną Hiszpanów, prawa pacjenta ewoluowały proporcjonalnie do procesów demokratyzacji i emancypacji obywatelskiej ${ }^{21}$. W 2002 r. wprowadzono wspomniany już Akt Autonomii Pacjenta, rozszerzający dotychczasowe prawa o szacunek dla autonomii i świadomą zgodę pacjenta. Jak należałoby się spodziewać, odchodzenie od paternalizmu następuje najbardziej dynamiczne wśród młodszych Hiszpanów. Największa świadomość praw pacjenta została odnotowana wśród ludzi poniżej 60. roku życia. Jednocześnie uważali oni, że dobrze rozumieją informacje udzielane przez lekarzy, poza tym wykazywali się najbardziej aktywnym podejściem do własnego leczenia i najbardziej krytycznie i refleksyjnie odnosili się do tego, jak byli traktowani przez personel medyczny. Jednakże, jak zaznaczają autorzy badań, znajomość konkretnych aktów prawnych w 2009 r., czyli 7 lat po wprowadzeniu $A k t u$, była wśród badanej próby ludzi nikła; jedynie $20 \% \mathrm{z}$ nich zdawało sobie sprawę z obowiązywania nowych regulacji prawnych ${ }^{22}$. Mimo to, ponad połowa wiedziała, że może odmówić podjęcia leczenia (co znacząco różni się od rezultatów podobnych badań przeprowadzonych np. w Turcji, gdzie jedynie $43 \%$ pacjentów wiedziało o prawie do odmowy leczenia $\left.{ }^{23}\right)$. Zwrócono także uwagę, że zwłaszcza w starszej grupie wiekowej kobiety były lepiej poinformowane o funkcjonowaniu opieki medycznej, co

${ }^{21}$ José J. Mira, Susana Lorenzo, Mercedes Guilaber, Virtudes Pérez-Jover, „Do Spaniards know their rights as patients?", International Journal for Quality Health Care 24, nr 4 (2012): 365, DOI: https://doi.org/10.1093/intqhc/mzs025

${ }^{22}$ Tamże, 365-367.

${ }^{23}$ Sezer Erer, Erme Atici, Ayşegül D. Erdemir, "The views of cancer patients on patient rights in the context of information and autonomy", Journal of Medical Ethics 2008, nr 34: 384-388. 
można tłumaczyć tym, że tradycyjnie kobiety były bardziej zaangażowane $\mathrm{w}$ opiekę nad chorymi w rodzinie.

Jak widzimy, wprowadzeniu prawa na rzecz autonomii pacjenta towarzyszy powolna, ale zdecydowana przemiana świadomości społecznej. Obywatele, nawet jeśli nie zdają sobie sprawy z dokładnego brzmienia ustawy, są coraz bardziej świadomymi i refleksyjnymi odbiorcami usług medycznych. Wydaje się, że poczucie sprawczości i możliwości samostanowienia w procesie leczenia wynika u pacjentów bardziej z ich poczucia podmiotowości obywatelskiej niż ze znajomości konkretnych paragrafów.

\section{Przemiany dyskursu bioetycznego w Hiszpanii}

Kwestie autonomii pacjenta są podnoszone również w bioetycznych sporach prowadzonych w Królestwie Hiszpanii. Ester Busquets, Begoňa Roman i Núria Terribas, próbując uchwycić istotę śródziemnomorskiego podejścia do bioetyki, stwierdzają, że na jej specyfikę składa się swoiste podejście do pojęcia autonomii pacjenta oraz duża waga katolicyzmu. Na wstępie trzeba zaznaczyć, że autorzy śródziemnomorskość rozumieją nie tyle jako kategorię geograficzną, czyli kraje leżące w rejonie basenu Morza Śródziemnego, co raczej kulturową. Chodzi im o kompleks kulturowy, obejmujący głównie Hiszpanię, Portugalię i Włochy, gdzie dominuje katolicyzm.

Autorzy krytycznie podchodzą do pojęcia autonomii pacjenta wypracowanego na gruncie kultury amerykańskiej, lub szerzej anglosaksońskiej, która nastawiona jest bardzo indywidualistycznie, podczas gdy w kulturze śródziemnomorskiej pojęcie osoby ma bardziej relacyjny i społeczny wymiar. W przeciwieństwie do bioetyki amerykańskiej, na południu Europy wciąż przeważa podejście paternalistyczne. Ponadto duże znaczenie w podejmowaniu decyzji medycznych ma nie tyle sam pacjent, co jego rodzina i najbliżsi ${ }^{24}$.

W 1976 r. w Barcelonie utworzono, z pomocą amerykańskiego propagatora bioetyki Daniela Callahana, pierwszy w Hiszpanii Instytut Bioetyczny. Trendy promujące pojęcie autonomii pacjenta docierały do Hiszpanii, Portugalii i Włoch od lat 70. XX w., jednakże nie zapuściły korzeni nad Morzem Śródziemnym

${ }^{24}$ Ester Busquets, Begoňa Roman, Núria Terribas, „Bioethics in Mediterranean Culture: the Spanish Experience”, Medicine, Health Care and Philosophy2012, nr 15: 437-439. 
ze względu na swój brak wrażliwości na kulturową specyfikę południa Europy, której obcy był amerykański indywidualizm. W Hiszpanii czy we Włoszech rodzina na przykład może wymagać od lekarzy, by nie ujawniali pacjentowi szczególnie niekorzystnej diagnozy. Poza tym rodzina aktywnie ingeruje w relacje między lekarzem a pacjentem. Specyfikę hiszpańskiego podejścia do medycyny określa także kulturowo ugruntowany głęboki szacunek do lekarzy i prestiż społeczny związany z tym zawodem, połączony z wysokim dystansem władzy, co może sprawiać, że w relacji z lekarzem pacjent nie postrzega siebie jako podmiot ${ }^{25}$.

Współczesną opiekę zdrowotną w Hiszpanii cechuje wysoki profesjonalizm lekarzy, a także poczucie misji społecznej związanej z publiczną opieką zdrowotną oraz inwestycje w nowe technologie i najnowsze wyposażenie. Za słabość systemu badacze uznają to, że rozwój gospodarki kapitalistycznej wykreował super-wymagających pacjentów, a właściwie super-wymagających klientów, którzy medycynę traktują jako kolejną komercyjną usługę. Również personel medyczny zaczął postrzegać pacjenta bardziej jako klienta. Następnie, w kontekście komercjalizacji usług medycznych nie ma jasnych rozróżnień między prawami, sprawiedliwością społeczną a osobistymi preferencjami czy zachciankami pacjentów. W efekcie pojawia się niebezpieczeństwo wykorzystywania systemu opieki zdrowotnej przez pacjentów, którzy żądają określonych usług medycznych, niekoniecznych dla zachowania zdrowia i życia, a na które nie mogą sobie pozwolić z prywatnych funduszy. Sytuację pogarsza to, że personel medyczny nie jest wystarczająco wyszkolony w zakresie komunikacji z pacjentami, poza tym lekarze nie są uwrażliwieni na kwestie autonomii pacjenta. Jak diagnozują autorzy, głównym problemem rozwoju bioetyki w Hiszpanii nie jest jej poziom akademicki, lecz zawodowy. W programach studiów medycznych bioetyka i etyka lekarska są obecne, ale wiedza teoretyczna w kontekście kultury o wysokim dystansie władzy nie zawsze przekłada się na postawy i sposoby zachowania wobec podopiecznych.

Kolejne zagrożenia to obecna sytuacja demograficzna i gwałtowne starzenie się społeczeństwa, nasuwające pytania o finansowanie służby zdrowia w przyszłości. Ogólnoświatowy kryzys ekonomiczny, który w 2008 r. mocno dotknął właśnie Hiszpanię, uwypuklił kwestie finansowe związane z medycyną. Lekarze w Hiszpanii natomiast, jak piszą Busquets, Roman i Terribas, ignorują ekonomiczny aspekt swojego zawodu ${ }^{26}$.

\footnotetext{
25 Tamże, 439.

${ }^{26}$ Tamże, 440.
} 
Zgodnie z hiszpańskim systemem politycznym, prawa pacjenta wynikają z pierwszorzędnych praw obywatela, a opieka medyczna nie jest komercyjną usługą, ale podyktowana jest misją niesienia pomocy. Obywatel rozumiany jest tutaj jako niezbywalny element nowoczesnego porządku politycznego, który zastąpił wcześniejsze typy więzi społecznej: pierwotne (primordial), religijne (sacred) i osobiste (personal). Obywatelskość oznacza wspólnotę ludzi, która wytworzyć się może, kiedy przekroczymy pierwotne więzi etniczne, religijne, a także osobisto-indywidualne, które kojarzyć można $\mathrm{z}$ roszczeniowym nastawieniem klienta ${ }^{27}$. Bioetyka w Hiszpanii ulega obecnie znaczącym przemianom, co podyktowane jest zmianą klimatu politycznego na tendencje państwowościowe i obywatelskie, którym towarzyszy odejście od katolicyzmu w sferze publicznej i krytyczne traktowanie wolnorynkowego kapitalizmu.

Jeśli idzie o wyzwania stojące przed hiszpańską bioetyką, według Busquets, Roman i Terribas, należałoby za takie uznać przezwyciężenie paternalizmu, promowanie autonomii pacjenta, szczególnie w kontekście tego, jak silny wpływ na jednostkę ma w kręgu kultury śródziemnomorskiej rodzina. Należy przy tym unikać biurokratyzacji, tak by autonomia pacjenta nie stała się kolejnym papierkowym obowiązkiem, polegającym na wypełnieniu formularzy, a jednocześnie pacjent nadal będzie niezdolny do wyegzekwowania swoich praw wobec personelu medycznego. Powinno się też oddzielać preferencje i zachcianki pacjentów - prowadzące czasem do niepotrzebnych lub wręcz szkodliwych interwencji medycznych - od autonomii pacjenta ${ }^{28}$.

Autorzy postulują, aby w Hiszpanii przyjąć model obywatelski, w którym opieka zdrowotna podyktowana będzie dobrem obywatela i wynikać będzie z obowiązków państwa wobec niego. Jednocześnie odżegnują się od komercjalizacji relacji terapeutycznej. Taka obywatelska formuła pozwala $\mathrm{z}$ jednej strony na zdystansowanie się od tradycji katolickiej, z drugiej zaś na wypracowanie laickiego odpowiedzialnego podejścia, stroniącego od wolnorynkowej tendencji dominującej w usługach medycznych np. w Stanach Zjednoczonych. Podstawową wartością, jak twierdzą autorzy, do której powinno się odnosić wszelkie kwestie sporne, ma być sprawiedliwość społeczna, a nie chrześcijańska dobroczynność czy Hipo-

${ }^{27}$ Edward Shils, „Primordial, personal, sacred and civil ties”, British Journal of Sociology 1957, nr 7: 113-145.

${ }^{28}$ Busquets, Roman, Terribas, „Bioethics”, 447. 
kratesowy obowiązek. Medycyna mieścić się musi w ramach państwa gwarantującego każdemu obywatelowi podstawową opiekę medyczną, będąc czynnikiem sprawiedliwości społecznej ${ }^{29}$.

W podobnym duchu kwestię związku państwa i bioetyki katolickiej definiuje Ana S. Iltis, chociaż wnioski, które wysnuwa są odmienne. Przypomnijmy, że wedle Busquets, Roman i Teribas, bioetyka powinna przyjąć model obywatelski; rozstrzygnięcia bioetyczne powinny być uwarunkowane sprawiedliwością społeczną, tak by z jednej strony uniknąć dominacji myślenia religijnego, które siłą rzeczy nie może dotyczyć osób areligijnych lub wyznawców innych religii, z drugiej zaś by uciec przed widmem wolnorynkowego i komercyjnego oraz skrajnie indywidualistycznego podejścia do medycyny. Iltis natomiast postrzega spory w bioetyce jako konflikt między kulturą katolicką a kulturą laicką ${ }^{30}$. Stwierdza, że te wojny kulturowe trwają już wiele lat, zwłaszcza w sprawach, w których nie można osiągnąć kompromisu, jak aborcja. Wynikają one z głęboko zakorzenionych odmienności w rozumieniu świata, a także z diametralnych różnic w kwestiach metafizycznych i aksjologicznych. Ana S. Iltis, inaczej niż Busquets, Roman i Teribas, nie widzi w bioetyce obywatelskiej sposobu na rozwiązania sporów ideologicznych, ponieważ uważa, że świeckie państwo w istocie swojej nie jest ideologicznie, ani aksjologicznie neutralne $e^{31}$.

Formułowana przez Busquets, Roman i Terribas propozycja stworzenia modelu obywatelskiego jest interesującą próbą wyjścia z prymatu bioetyki ukierunkowanej religijnie (w tym przypadku zorientowanej katolicko), jednocześnie pozwala na uwzględnienie specyfiki kulturowej krajów śródziemnomorskich, ale bez popadania w komercjalizację medycyny i bez uciekania się do rozwiązań skrajnie indywidualistycznych. Jednak i ta koncepcja narażona jest na krytykę, że w istocie pod przykrywką neutralności promuje określony, laicki system wartości, co niekoniecznie odpowiada przedstawicielom bioetyki katolickiej.

\section{Liberalizacja prawa reprodukcyjnego w Hiszpanii}

Debata bioetyczna w Hiszpanii rozpoczęła się na dobre od konfrontacji zachowawczej hierarchii kościelnej ze środowiskami progresywnymi i lewicowymi,

\footnotetext{
${ }^{29}$ Tamże, 447-499.

${ }^{30}$ Ana S. Iltis, „Bioethics and the Culture Wars”, Christian Bioethics 17, nr 1 (2011): 9-24.

${ }^{31}$ Tamże, 21-22.
} 
dążącymi do zasadniczej zmiany społecznej i kulturowego przewartościowania. Ostre spięcia między obozem lewicowym a katolickim wynikają z przyczyn historycznych i politycznych. Już w czasach rekonkwisty Kościół rzymsko-katolicki zyskał silną pozycję na półwyspie. Z drugiej jednak strony najnowsza historia Hiszpanii naznaczona jest frankizmem, który trwał prawie czterdzieści lat od $1936 \mathrm{r}$. do śmierci Francisco Franco w 1975 r. Czasy te charakteryzowały się silnymi postawami nacjonalistycznymi i antydemokratyczną dyktaturą, krwawo zwalczano republikańską i lewicową opozycję, prześladowano mniejszości narodowe (Basków) oraz etniczne (Katalończycy). Jednocześnie reżim Franco był wspierany przez Kościół. Po upadku dyktatury i nastaniu demokracji pojawiły się silne reakcje antyklerykalne.

U schyłku frankizmu, w przeobrażeniach demokratycznych dużą rolę odegrały oddolne inicjatywy społeczne. Ruchy obywatelskie, podobnie jak w czasie przemian antykomunistycznych w Polsce - zrzeszające ludzi w formie związków zawodowych, tworzyły zręby demokratycznego pluralizmu ${ }^{32}$. Procesy demokratyczne w Hiszpanii osiągnęły swoją kulminację w 1978 r. w postaci konstytucji, która gwarantowała prawo do życia, fizycznej integralności, wolności, szacunku i prywatności, a także prawo do tworzenia rodziny i opieki medycznej.

Wyrazem gwałtownych przemian w Hiszpanii są znaczne zmiany legislacyjne, znamionujące odejście od katolickich tradycji. W 1979 r. wprowadzono regulację dotyczącą transplantacji, a w 1988 r. prawo odnoszące się do wspomaganej reprodukcji33. Natomiast na początku XXI w. nastąpiła legalizacja małżeństw osób tej samej płci oraz reforma prawa aborcyjnego na znacznie bardziej liberalne. Aborcja do 1985 r. była całkowicie zakazana, w 2010 r. w Ley Organica 2/2010 34 dopuszczono możliwość aborcji na żądanie do 14 tygodnia ciąży, później jest ona legalna w przypadku zagrożenia życia matki lub stwierdzenia ciężkiej nieuleczalnej choroby lub malformacji płodu.

W 2006 r. zreformowano zasady dotyczące wspomaganej reprodukcji. Wprowadzono obowiązek wydawania przez rodziców dyspozycji odnoszącej się

${ }^{32}$ Zob. Robert M. Fishman, „The Labor Movement in Spain. From Authoritarianism to Democracy", Comparative Politics 13, nr 3 (1982): 281-305.

${ }^{33}$ Busquets, Roman, Terribas, „Bioethics”, 442.

${ }^{34}$ Ley Orgánica 2/2010, de 3 de marzo, de salud sexual y reproductiva y de la interrupción voluntaria del embarazo, https://www.boe.es/buscar/act.php?id=BOE-A-2010-3514 (dostęp 24.09.2019). 
do przyszłego losu zbędnych zarodków (zamrożenie i przechowywanie, zniszczenie, lub wykorzystanie do celów naukowych). Wprowadzono również prawo legalizujące $\mathrm{w}$ artykule 12 preimplantacyjną diagnostykę genetyczną (PDG) nie tylko w celu wykluczenia chorób u potomstwa, ale również selekcji embrionów ze względu na zgodność tkankową z potrzebującym transplantacji krewnym ${ }^{35}$.

Preimplantacyjna diagnostyka genetyczna jest oferowana w Hiszpanii przez państwową i prywatną służbę zdrowia, zapewnia ona skanowanie embrionów pod kątem jednogenowych chorób genetycznych, takich jak mukowiscydoza, choroba Huntingtona etc. i aberracji chromosomalnych (np. zespół Downa). Placówki te oferują również badania na choroby skojarzone z chromosomem $\mathrm{X}$, ale nie uznają niemedycznej selekcji ze względu na płeć. Narodowy Komitet do spraw Wspomaganej Reprodukcji konsultuje kontrowersyjne przypadki użycia PDG, jak selekcja embrionów pod względem zgodności tkankowej wobec rodzeństwa cierpiącego na schorzenie wymagające transplantacji np. szpiku kostnego ${ }^{36}$. Obecnie Hiszpania jest miejscem, gdzie podróżują pary starające się właśnie o taką procedurę z takich krajów, jak Portugalia, Włochy, Niemcy czy Turcja; w przeszłości to Hiszpanie w tym celu podróżowali do USA lub Belgii.

Jeśli chodzi o progresywne podejście do badań biomedycznych uznać można Hiszpanię za lidera w Europie, obok równie liberalnej Wielkiej Brytanii. W obu krajach dopuszcza się bowiem badania na ludzkich embrionalnych komórkach macierzystych oraz na pre-embrionach, pozostałych po terapii in vitro, do 14 dnia rozwoju ${ }^{37}$. Jednocześnie wyraźnie widać, że przyjęcie tych zapisów prawnych świadczy o osłabieniu roli nauki Kościoła katolickiego w kształtowaniu bioetyki w Hiszpanii, wszystkie one są bowiem sprzeczne z nauką kościelną dotyczącą statusu życia prenatalnego, która wyklucza dokonywanie aborcji, sztucznego zapłodnienia, preimplantacyjnej diagnostyki genetycznej czy badań na embrionach.

\section{Podsumowanie}

${ }^{35}$ LEY 14/2006, de 26 de mayo, sobre técnicas de reproducción humana asistida, https://www.institutobernabeu.com/upload/ficheros/ley_de_reproduccion_asistida_2007.pdf\#page=1 \&zoom=auto,-107,842 (dostęp 24.09.2019).

${ }^{36}$ Eleni Zika I inni, Preimplantation Genetic Diagnosis in Europe (Sewilla: European Commission, 2007), 48-50.

${ }^{37}$ Busquets, Roman, Terribas, „Bioethics”, 443. 
Kulturowa bioetyka Hiszpanii opiera się na odrzuceniu komercjalizacji medycyny przy jednoczesnym zróżnicowanym stosunku do dziedzictwa chrześcijańskiego. Bioetycy katoliccy wyraźnie optują za nauczaniem Kościoła, opierającym się na autorytecie prawd objawionych. Z kolei grupa aktywnych myślicieli dąży do sekularyzacji systemu, czego skutkiem jest zmiana hiszpańskiego prawa na bardziej liberalne w sprawach aborcji, PDG czy badań na embrionalnych komórkach macierzystych. W Hiszpanii istotnym pojęciem bioetycznym stał się obywatel jako podmiot odróżniany z jednej strony od pojęć religijnych, z drugiej - od relacji konsumenckich, tak aby pacjent nie był traktowany jako klient, jak to często dzieje się w krajach zachodnich. Zmierza się jednocześnie do przezwyciężenia paternalistycznych relacji miedzy pacjentem a personelem medycznym na poziomie prawa, akcji społecznych i przemian świadomości ludzi. Rola rodziny i osób bliskich w podejmowaniu decyzji została zachowana, ale ograniczona do sytuacji, gdy pacjent nie jest zdolny do wydania świadomej zgody, a nie posiada formalnego pełnomocnika.

Pozytywna recepcja koncepcji szacunku dla autonomii pacjenta nie jest bezkrytycznym przyjęciem amerykańskiego pryncypializmu, dąży się bowiem do połączenia pojęcia opieki medycznej jako misji społecznej z duchem obywatelskim. Dzieje się to zarówno na poziomie prawa, świadomości społecznej, aktywności obywatelskiej, a także w wymiarze krytycznej refleksji nad katolickim dziedzictwem kraju. Dąży się do wypracowania własnego, przystępniejszego kulturowo i politycznie modelu bioetyki. Jednocześnie tak pojęta bioetyka obywatelska, jeśli będzie konsekwentnie realizowana, stanowić może rozwiązanie dla innych krajów, aby wyrwać się z oków tradycyjnego paternalizmu, ale jednocześnie nie popaść w Charybdę skrajnie indywidualistycznie i subiektywistycznie rozumianej autonomii pacjenta, która pojmowana rozłącznie wobec pojęcia poczucia odpowiedzialności społecznej, doprowadzić może skrajnej komercjalizacji medycyny, a w efekcie do pogłębienia podziałów społecznych. 
Pobrane z czasopisma http://kulturaiwartosci.journals.umcs.pl

\section{Bibliografia}

Affinity Group of National Associations AGNA, https://www.civicus.org/index.php/what-wedo/strengthen/agna Dostęp 24.09.2019.

Babis, Deby. "The role of civil society organizations in the institutionalization of indigenous medicine in Bolivia”. Social Sciences in Medicine 2014, nr 123: 287-294.

Busquets, Ester, Roman, Begoňa, Terribas, Núria. „Bioethics in Mediterranean Culture: the Spanish Experience". Medicine, Health Care and Philosophy 2012, nr 15: 437-439.

Civil Society, and Health. Contribution and Potential. Red. Scott L. Green, Matthias Wismar, Gabriel Pastorino, Monika Kosinska. UK: WHO, 2017.

Cohen, Jean L., Arato, Andrew. Civil Society and Political Theory. Cambridge: MIT Press, 1992.

Entwistle, Vikki A., Stacy M. Carter, Alan Cribb, Kirsten McCaffery, „Supporting patient autonomy: the importance of clinician-patient relationships". Journal of general internal medicine 25, nr 7 (2010): 741-745. DOI:10.1007/s11606-010-1292-2

Erer, Sezer, Erme Atici, Ayşegül D.Erdemir, „The views of cancer patients on patient rights in the context of information and autonomy". Journal of Medical Ethics 2008, nr 34: 384-388.

Fishman, Robert M. „The Labour Movement in Spain. From Authoritarianism to Democracy”. Comparative Politics 13, nr 3 (1982): 281-305.

García-Armesto, Sandra, María Begoña Abadía-Taira, Antonio Durán. „Spain: Health System Review 2010". Health System in Transition 12, nr 4 (2010): XX-XXIII.

Giarelli, Guido, Ellen Annandale. „Introduction: the role of civil society in healthcare system reforms". Social Science and Medicine 2014, nr 123: 160-167.

Habermas, Jürgen. Legitimation Crisis. Tłum. Thomas Mc Carty. Boston: Beacon Press, 1975.

Iltis, Ana S. „Bioethics and the Culture Wars”. Christian Bioethics 17, nr 1 (2011): 9-24.

Ley 14/2006, de 26 de mayo, sobre técnicas de reproducción humana asistida, https://www.institutobernabeu.com/upload/ficheros/ley_de_reproduccion_asistida_200 7.pdf\#page $=1 \&$ zoom $=$ auto, $-107,842$ Dostęp 24.09.2019.

Ley 41/2002, de 14 de noviembre, básica reguladora de la autonomía del paciente y de derechos y obligaciones en materia de información y documentación clínica,

https://www.boe.es/buscar/doc.php?id=BOE-A-2002-22188 Dostęp 24.09.2019.

Ley Orgánica 2/2010, de 3 de marzo, de salud sexual y reproductiva y de la interrupción voluntaria del embarazo, https://www.boe.es/buscar/act.php?id=BOE-A-2010-3514 Dostęp 24.09.2019.

Mira, José, J., Susana Lorenzo, Mercedes Guilaber, Virtudes Pérez-Jover. „Do Spaniards know their rights as patients?" International Journal for Quality Health Care 24, nr 4 (2012): $365-367$.

Moazam, Farhat. Bioethics and Organ Transplantation in a Muslim Society. A Study in Culture, Ethnography, and Religion. Indianapolis: Indiana University Press, 2006.

„Podwale 7”, http://podwale-siedem.pl/stowarzyszenie-statut/ Dostęp 24.09.2019. 
Sevillano, Ellena G. „Sanidad Reunicia Definitivamente a la Privatización Hospitalaria”. El Pais, 04.11. 2014, https://elpais.com/ccaa/2014/04/11/madrid/1397239898_967369.html Dostęp 24.09.2019.

Shils, Edward. „Primordial, personal, sacred and civil ties”. British Journal of Sociology 1957, nr 7 (1957): 113-145.

Stiggelbout, Anne M., „Ideals of patient autonomy in clinical decision making: a study on the development of a scale to assess patients' and physicians' views". Journal of medical ethics 30, nr 3 (2004): 268-274. DOI:10.1136/jme.2003.003095

Tocqueville, Alexis, de. O demokracji w Ameryce. Tłum, Marcin Król. Warszawa: Państwowy Instytut Wydawniczy, 1976.

Zika, Eleni, Corveleyn, Anniek Corveleyn, Michael Morris, Elisabeth Dequeker, James Lawford Davies, Karen Sermon, Guillermo Antiñolo, Andreas Schmutzler, Jiri Vanecek, Fransesc Palau, Dolores Ibarreta, Preimplantation Genetic Diagnosis in Europe. Sevilla: European Commission, 2007.

\section{Summary}

The patient as a citizen.

Patient's autonomy and civic virtue as seen in Spain

The paper focuses on the changing perception of bioethics and the patient's autonomy in Spain where paternalism and Catholic Church teachings shaped relationships between physicians and patients for many long years. The country's political transformation following the collapse of Francisco Franco's dictatorship (1936-1975) has also brought major changes on matters of bioethics. The growing sense of civic virtue has enhanced the importance of the patient's autonomy in medicine. This manifests itself on several levels: in legislation (law on patient's autonomy), in the social field (NGOs operating in medical care), in growing awareness of patients' rights and critical approach to relations with medical professionals) as well as in ideology (criticism of paternalism, civic bioethics, disapproval of commercialization in medicine). Moreover, the specificity of the current situation in Spain is also determined by a re-evaluation of the Catholic Church's heritage and abandonment of its teachings in civic bioethics and consequently, by liberalization of the abortion law as well as enactment of legal regulations on assisted reproduction, pre-implantation genetic diagnosis and embryo research.

Keywords: patient's autonomy, paternalism, civic society, Spain 
Pobrane z czasopisma http://kulturaiwartosci.journals.umcs.pl

Agata Strządała, Pacjent jako obywatel. Autonomia pacjenta i obywatelskość...

\section{Zusammenfassung}

\section{Der Patient als Bürger. Die Autonomie des Patienten und die Bürgerschaft am Beispiel Spaniens}

Der Beitrag untersucht den Wandel in der Auffassung der Autonomie des Patienten in Spanien, wo in den Beziehungen zwischen dem Arzt und dem Patienten traditionsgemäss der Paternalismus und in der ideologischen Sphäre die Lehre der katholischen Kirche herrschte. Die Systemumwandlung im Land nach dem Untergang der Diktatur von Francisco Franco (1937-1975) führte zu bedeutenden Umwandlungen auch in der Frage der Bioethik. Das wachsende Gefühl der Bürgerschaft verband sich dort mit der zunehmenden Bedeutung der Autonomie des Patienten, was auf einigen Stufen in Erscheinung trat: der legislatorischen Stufe (das Recht auf Autonomie des Patienten), der gesellschaftlichen (die im Bereich der Gesundheitsfürsorge tätigen Nichtregierungsorganisationen), der Bewusstseinsstufe (die Zunahme am Bewusstsein der Patientenrechte, die reflexive Betrachtung der Beziehung zum medizinischen Personal) und der ideologischen Stufe (die Kritik des Paternalismus, bürgerliche Bioethik, die Kritik an der Kommerzialisierung der Medizin). Darüber hinaus entscheidet über die Eigenart der aktuellen Situation in Spanien die Umwertung des katholischen Erbes und die Abkehr von der Kirchenlehre im bürgerlichen Modell der Bioethik, die sich in der Liberalisierung des Abtreibungsrechts, des Rechts auf unterstütze Fortpflanzung, genetische Präimplantationsdiagnostik und Forschungen auf Embryos manifestiert.

Schlüsselworte: Autonomie des Patienten, Paternalismus, Bürgergesellschaft, Spanien

Information about Author:

AGATA STRZĄDAŁA, Ph.D., Department of Humanistic Sciences in Medicine, Faculty of Medicine, Wroclaw Medical University; address for correspondence: ul. J. Mikulicza-Radeckiego 7, PL 50368 Wrocław; e-mail: agata.strzadala@umed.wroc.pl 